\title{
Cost-benefit relation of diet and probiotics in iatrogenic bowel irregularity (IBI)
}

\author{
Eric Claassen $^{1,2 *}$ \\ ${ }^{1}$ Department of Virology, Erasmus Medical Center, Rotterdam, Netherlands \\ ${ }^{2}$ Athena Institute, Vrije Universiteit, Amsterdam, Netherlands \\ *Correspondence: prof.eric.claassen@gmail.com
}

Edited by:

Dominique J. Dubois, Université Libre de Bruxelles, Belgium

Reviewed by:

Koen Venema, Beneficial Microbes Consultancy, Netherlands

Keywords: probiotic, prevention, bowel, irregularity, antibiotic-associated diarrhea (AAD), Clostridium difficile-associated diarrhea (CDAD)

\section{INTRODUCTION}

In this issue Lenoir-Wijnkoop et al. (2014) show that an affordable and widely available fermented dairy drink containing a known and well-documented probiotic could lead to health care system cost savings. This paper is just one in a surprisingly large number of very recent papers on probiotics, antibiotic-associated diarrhea (AAD), and Clostridium difficileassociated diarrhea (CDAD, recurrentCDAD, or CD infection: $\mathrm{CDI}$ ). The revival of attention for CDI is mainly caused by the emergence of new hyper virulent strains, a decrease of clinical response to antibiotics, an increase of incidence and prevalence and the existence of at least three different toxins. Clostridium difficile has a broad clinical manifestation from asymptomatic (contagious) carriers, via diarrhea toward pseudomembranous colitis, toxic megacolon, and death. Since Clostridium difficile is a spore former it can still cause endogenous self-contamination even (or especially) after antibiotic treatment. Furthermore, these spores are a contamination hazard in health care facilities and they heighten the transmission rates ( $R$-value). Taken together, all these factors (reviewed in Hell et al., 2013) result in a high unmet medical need with significant socio-economic impact. Here, we would like to put both the clinical and economic impact of this paper in a broader "state of the art" context, by adding alternative new insights and references not yet available to the Lenoir-Wijnkoop paper.

\section{COST}

The total cost of AAD, CDAD, and CDI is dependent on the calculation method used, as discussed at length in the LenoirWijnkoop paper, but is in the order of several tens of billions of dollars annually. Direct cost of recurrent CDAD/CDI ranges from 2000 (USA) to 3000 (UK) euro per case/year with health care system costs in the range of 4-6000 euro's peaking as high as 11,000 euro for recurrentCDI (reviewed in Hell et al., 2013). The added, and real, cost to society is much higher. Use of "double" doses probiotics in Canada (where 1 in 10 CDI patients succumbs to the disease) resulted in cost savings of up to a 1000 euro per patient ( $n=1000$ patients; Fansi et al., 2012).

\section{RE-POOP-ULATION WITH DONOR FECES}

Repoopulation, a term originally coined by Petrof et al. (2013) based on their astonishing results, pertains to the re-balancing of an aberrant microbiota by infusing donorfeces. In a very recent double blind placebo controlled study (RCT), recurrent CDI could be solved in over $80 \%$ of investigated cases by duodenal infusion of donorfeces, where vancomycin resolved disease in $31 \%$ and vancomycin in combination with bowel lavage in only $23 \%$. These results were so dramatic that the RCT was stopped, after independent review in an interim analysis, in order to provide feces transplantation to the placebo group (Van Nood et al., 2013). Feces transplantation is under discussion with the FDA for presumed safety issues (but still allowed for recurrent CDI) and remains a costly procedure. The high price and even a ban on repoopulation has also led to (unwise and unwanted) do it yourself repoopulation instruction videos on the internet. Clearly, reintroducing a complete new microbiota is a long way from managing the same problem with a fermented dairy drink with one to ten selected strains of lactic acid bacteria.

\section{UNMET MEDICAL NEED}

AAD and CDAD are only two of several forms of bowel irregularity introduced by medical intervention. Other iatrogenic bowel irregularities (IBI) are introduced for instance by: enteral-nutritiondeficiencies, hospital diet, colonoscopydamage/perforation, trauma, stress, therapeutic irradiation, colectomy-associated-pouchitis or-short-bowel-syndrome, surgery, chemotherapy, morphine and other medicines, hospital infections, and the length of time people are bedridden (general lack of exercise). These factors can deregulate normal gut motility and gut function. Moreover, they can influence the living microbiota $\left(10^{14} \mathrm{bac}-\right.$ teria) of the gut. However, it should be stressed that most of these IBI are usually mild and self-limiting, but in some cases this can lead to persistent or recurrent obstipation or diarrhea, prolonged hospital stay, serious complications, and death (Hell et al., 2013). The incidence of CDAD and CDI varies greatly from center to center and has an enormous impact on the outcome of the study. When event rates are much lower than predicted, the resulting low absolute risk reduction might interfere with significance even in large and overpowered studies (Daneman, 2013). So there is an enormous centerto-center variation in $\mathrm{CD}$-associated problems and when incidence of CDAD is lower than $1.2 \%$ probiotics might not 
be cost effective, as recently shown in a meta-analysis based on all available data (Daneman, 2013). However, recently it was also shown that in a 240 bed hospital over the course of 22 months almost two thousand patients were treated for a (presumed) C. dif issue. Eventually, only $15 \%$ (!) had lab confirmed positive tests (unpublished, see Wickline, 2013). Consequently, from premature babies with NEC (necrotizing enterocolitis) via healthy adults with weight (Mekkes et al., 2013) or bowel problems, right through to the elderly, bowel irregularities (in need of bona fide diagnostics) cause significant morbidity and mortality and form a largely unmet medical need throughout even a relatively "healthy" life (Islam et al., 2012; Weenen et al., 2013a).

\section{DIET, PROBIOTICS, AND PREBIOTICS}

Prebiotics are non-digestible food ingredients that stimulate the growth and/or activity of bacteria in the digestive system in ways claimed to be beneficial to health (i.e., linked to stimulation of probiotics). They were first identified and named by Marcel Roberfroid in 1995 and are also known as oligosaccharides or solublefibers (not to be confused with food fiber). Human milk oligosaccharides (HMOS) represent the third most abundant component of human breast milk. More than a hundred structurally distinct HMOS have been identified. Recent studies have started to link individual HMOS to infant health and disease and suggest the importance of a mother-infant match with regard to HMOS composition (Marx et al., 2014). Milk from domestic mammals has 10-100 fold less oligosaccharides than human milk (Table 1). Oligosaccharides like galacto(GOS) and fructo-oligosaccharides (FOS, including inulin) are routinely added to most infant formulas and are also available in powdered form. It has long been known that diets supplemented with GOS and FOS have a prebiotic effect, encouraging the growth of our "endogenous probiotics" like bifidobacteria and reducing opportunistic pathogens like Escherichia coli, Bacteroides spp, and Clostridium spp. Barrett (2013). Paradoxically, prebiotics should not be added to probiotics during GI transit because they cause a switch from logarithmic to stationary growth phase (Golowczyc et al., 2013) which lowers their resistance to gastric acid (low $\mathrm{pH}$ ) and bile, by lowering the expression of stress proteins (personal communication Dr. K. Venema). On the other hand, metabolizable sugars (like glucose) provide ATP via glycolysis thereby enabling proton exclusion potentially enhancing survival during gastric transit (Corcoran et al., 2005). Next to these indirect prebiotic effects in the gut, GOS, and FOS also have direct effects, such as pathogen-adhesion-inhibition to the gut epithelium and modulating binding of selectins (Barrett, 2013; Roberts et al., 2013). Consequently taking probiotics with small amounts of sugar helps the strains to survive gastric and bile juices. In the diet, the vegetables that contain relatively large amounts of oligosaccharides (like inulin) are, strangely enough, not the ones we use when experiencing IBI (iatrogenic bowel irregularities) like e.g., diarrhea. Furthermore, the first eight vegetables in the list are routinely found in a Mediterranean diet. Hospital dieticians and cooks could use the data of the LenoirWijnkoop study in conjunction with high GOS and FOS foods for synergy (known as synbiotics) and enhance the calculated beneficial effects by minor dietary interventions at marginal extra cost.

\section{FOOD-PHARMA CONVERGENCE AND REGULATIONS}

As we described recently, industries are converging at the Food-Pharma interface and work in different regulatory and reimbursement areas on either functional foods or medical foods (Weenen et al., 2013b). Remarkably, although the core technology domain is food within the medical-food industry the technological development is mainly driven by pharmaceutical/pharmacological technologies. When classified as functional foods, probiotic effects pertaining to human health, consist of claims subject to evaluation by regulatory institutes such as the European Food Safety Authority (EFSA) Panel on Dietetic Products, Nutrition and Allergies (NDA). As recently reviewed $78 \%$ of all analyzed health claims are considered by the NDA Panel as (possibly) beneficial to human health, in particular the gut health effects. However, in many cases, the scientific substantiation of a particular health claim, when analyzed in a Pharma like manner, was deemed insufficient,
Table 1 | Prebiotics, (a.k.a. soluble fibers) improving growth of probiotic bacteria, as found in dietary components and milk ranked by quantitative availability.

Recovered oligosaccharides as

$\%$ weight/weight fresh

Chicory/endive stalks

$15-20$

Garlic

9-16

Black salsify and leek

$4-10$

Onion and artichoke

2-6

Asparagus

2-3

Wheat

$1-4$

Oats (and human breast milk)

$0.5-1.5$

Banana

$0.3-0.7$

Domestic-placental-mammal milk $\quad 0.01-0.1$

and most applications were turned down (Binnendijk and Rijkers, 2013). Currently, there is a vivid debate as to whether functional foods should be indeed regulated more stringently as medical foods (as EFSA is now doing), the largely EU-policydriven outcome is eagerly awaited by scientists, clinicians and industry alike (Hill and Sanders, 2013). For near-future health claim applications concerning probiotics to be successful, they should include precise dose and strain specifications, specific statements on what exactly the microorganism affects, and overpowered intent to treat (ITT) analysis of the clinical trials in the targeted (general) population. An excellent and recent example of how such study should be performed along those very stringent guidelines, convincingly showing a dose-dependent 50\% reduction of $A A D$ with a probiotic mixture was published by Ouwehand et al. (2014).

\section{SAFETY}

Recently we systematically studied adverse events as related to probiotics, in all placebo controlled RCT's those AEs found were considered unrelated to the study product (which was also well-tolerated), and there were no major safety concerns in either verum or placebo. However, inconsistent, imprecise, and potentially incomplete reporting as well as the variation in probiotic strains, dosages, administration regimes, study populations and reported outcomes, greatly limits the generalizability of conclusions and argues convincingly for obligatory, and standardized behavior on adverse events (CTCAE) reporting in "food" studies (Van den Nieuwboer et al., 
2014). The safety, quality, and quantity (CFU), specifically in relation to antibiotic sensitivity, of medicinal products containing probiotics also needs to be established as recently and satisfactorily done for Polish products (Wiatrzyk et al., 2013).

\section{DOSE AND PRODUCT CHOICE}

Without going into too much detail it is clear from literature that probiotics work in a dose-dependent manner with effectiveness for AAD or CDAD at or around 10-17 billion bacteria per day (e.g., double dose in Lenoir-Wijnkoop study and Ouwehand et al., 2014). Most products on the market do not contain those high numbers. However, the dosing is straindependent and dose-response relations need to be established for each different strain/product or cocktail/combination (Hell et al., 2013). Moreover, recently Douillard et al. (2013) showed that the draft genomes of two competing brands of dairy drink based probiotic products are close to identical to each other and differ by no more than minor chromosomal re-arrangements, substitutions, insertions, and deletions, as evident from the verified presence of one insertion-deletion (InDel) and only 29 single-nucleotide polymorphisms (SNPs). Their observations could imply that results obtained in human experiments performed with the Actimel $^{\circledR}$ (as used in the LenoirWijnkoop study) and Yakult ${ }^{\circledR}$ strains can be compared with each other as these strains share a recent common ancestor. Nevertheless, as the human intervention trials are not conducted on the strains only but mainly on the final food form (matrix/sugar/additives), in accordance with the current regulation, and therefore differences in matrix, the bacterial composition and metabolites can lead to significant differences in outcomes. Similar relations could exist for other, competing products in the market and accentuate the EFSA call for full genome sequencing identification data and clear and detailed description of matrix and formulation. Finally, dose and product choice also has an impact when comparing single- and multi species/strain products. As recently shown in the Allen study (cfr Daneman, 2013) not all strain/species/dose combinations will perform effectively. However, this and other negative studies have barely any impact on the meta-analysis outcome of the accepted effectiveness of (working) probiotics in AAD (Cochrane review by Goldenberg et al., 2013). Furthermore, such negative studies are less convincing when only low incidence (and consequently low absolute risk reduction) of CDAD or AAD are found in the control group (Daneman, 2013).

\section{CONCLUSIONS}

As described in the Lenoir-Wijnkoop paper in this issue a new and effective generation of probiotic products, in which all aspects of health, disease, and pathogenexclusion are incorporated, is emerging (cfr also: Hell et al., 2013; Ouwehand et al., 2014). When given orally and in the right dose in combination with exercise and an appropriate diet, probiotics can give a clear healthcare system cost reduction for several forms of IBI with notable examples like AAD, CDAD, and CDI. Probiotics are safe and reduce disease/antibiotic-related adverse events by at least $20 \%$. Treatment dose and protocols are product- and strain-dependent. Studies combining biological, clinical, and economic data help predict whether the benefits of a protocol or policy (e.g., probiotics and diet) outweigh its costs. Perfect evaluation of all present and future costs and benefits is challenging, but ranking of best alternatives should result in economic efficiency and social welfare in vulnerable patient groups.

\section{ACKNOWLEDGMENTS}

Profs Drs. Johan Garssen, Yvan Vandenplas, Koen Venema, Robert-Jan Brummer, and Linda Wanders are thanked for technical and clinical suggestions and guidance with unpublished information.

\section{REFERENCES}

Barrett, J. S. (2013). Extending our knowledge of fermentable, short-chain carbohydrates for managing gastrointestinal symptoms. Nutr. Clin. Pract. 28, 300-306. doi: 10.1177/0884533613485790

Binnendijk, K. H., and Rijkers, G. T. (2013). What is a health benefit? an evaluation of EFSA opinions on health benefits with reference to probiotics. Benef. Microbes 4, 223-230. doi: 10.3920/BM2013.0019

Corcoran, B. M., Stanton, C., Fitzgerald, G. F., and Ross, R. P. (2005). Survival of probiotic lactobacilli in acidic environments is enhancedin the presence of metabolizable sugars. Appl. Environ. Microbiol. 71, 3060-3067. doi: 10.1128/AEM.71.6.3060-3067.2005
Daneman, N. (2013). A probiotic trial: tipping the balance of evidence? Lancet 382, 1228-1230. doi: 10.1016/S0140-6736(13)61571-8

Douillard, F. P., Kant, R., Ritari, J., Paulin, L., Palva, A. and de Vos, W. M. (2013). Comparative genome analysis of Lactobacillus casei strains isolated from Actimel and Yakult products reveals marked similarities and points to a common origin. Microb. Biotechnol. 6, 576-587. doi: 10.1111/17517915.12062

Fansi, A. A. K., Guertin, J. R., and LeLorier, J. (2012). Savings from the use of a probiotic formula in the prophylaxis of antibioticassociated diarrhea. J. Med. Econ. 15, 53-60. doi: 10.3111/13696998.2011.629015

Goldenberg, J. Z., Ma, S. S. Y., Saxton, J. D., Martzen, M. R., Vandvik, P. O., Thorlund, K., et al. (2013). Probiotics for the prevention of Clostridium difficile associated diarrhea in adults and children (Review) The Cochrane collaboration. Cochrane Database Syst. Rev. 5:CD006095. doi: 10.1002/14651858.CD006095. pub3

Golowczyc, M., Vera, C., Santos, M., Guerrero, C., Carasi, P., Illanes, A., et al. (2013). Use of whey permeate containing in situ synthesised galacto-oligosaccharides for the growth and preservation of Lactobacillus plantarum. J. Dairy Res. 80, 374-381. doi: 10.1017/S002202991 3000356

Hell, M., Bernhofer, C., Stalzer, P., Kern, J. M., and Claassen, E. (2013). Probiotics in Clostridium difficile infection: reviewing the need for a multistrain probiotic. Benef. Microbes 4, 39051. doi: 10.3920/BM2012.0049

Hill, C., and Sanders, M. E. (2013). Rethinking "probiotics." Gut Microbes 4, 269-270. doi: 10.4161/gmic. 25143

Islam, J., Cohen, J., Rajkumar, C., and Llewelyn, M. J. (2012). Probiotics for the prevention and treatment of Clostridium difficile in older patients. Age Ageing 41, 706-711. doi: 10.1093/ageing/ afs077

Lenoir-Wijnkoop, I., Nuijten, M. J. C., Craig, J., and Butler, C. C. (2014). Nutrition economic evaluation of a probiotic in the prevention of antibioticassociated diarrhea. Front. Pharmacol. 5:13. doi: 10.3389/fphar.2014.00013

Marx, C., Bridge, R., Wolf, A. K., Rich, W., Kim, J. H., and Bode, L. (2014). Human milk oligosaccharide composition differs between donor milk and mother's own milk in the NICU. J. Hum. Lact. 30, 54-61. doi: 10.1177/0890334413513923

Mekkes, M. C., Weenen, T. C., Brummer, R. J., and Claassen, E. (2013). The development of probiotic treatment in obesity. Benef. Microbes 25, 1-10. doi: 10.3920/BM2012.0069

Ouwehand, A. C., DongLian, C., Weijian, X. Stewart, M., Ni, J., Stewart, T., et al. (2014) Probiotics reduce symptoms of antibiotic use in a clinical setting: a randomized dose response study. Vaccine 32, 458-463. doi: 10.1016/j.vaccine. 2013.11.053

Petrof, E. O., Claud, E. C., Gloor, G. B., and AllenVercoe, E. (2013). Microbial ecosystems therapeutics: a new paradigm in medicine? Benef. Microbes 4, 53-65. doi: 10.3920/BM2012.0039

Roberts, C. L., Keita, A. V., Parsons, B. N., Prorok-Hamon, M., Knight, P., Winstanley, C., 
et al. (2013). Soluble plantain fibre blocks adhesion and M-cell translocation of intestinal pathogens. J. Nutr. Biochem. 24, 97-103. doi: 10.1016/j.jnutbio.2012.02.013

Van den Nieuwboer, M., Claassen, E., Morelli, L., Guarner, F., and Brummer, R. J. (2014). Probiotic and synbiotic safety in infants under two years of age. Benef. Microbes. doi: 10.3920/BM2013.0046. [Epub ahead of print].

Van Nood, E., Vrieze, A., Nieuwdorp, M. D., Fuentes, S., Zoetendal, E. G., De Vos, W., et al. (2013). Duodenal Infusion of donor feces for recurrent Clostridium difficile. J. Med. 368, 407-415. doi: 10.1056/NEJMoa1205037

Weenen, T. C., Jentink, A., Pronker, E. S. Commandeur, H. R., Claassen, E., Boirie, Y., et al. (2013a). Patient needs and research priorities in the enteral nutrition market-a quantitative prioritization analysis. Clin. Nutr. doi: 10.1016/j.clnu.2013.11.002. [Epub ahead of print].

Weenen, T. C., Ramezanpour, B., Pronker, E. S. Commandeur, H. R., and Claassen, E. (2013b). Food-pharma convergence in medical nutritionbest of both worlds? Plos ONE 8:e82609. doi: 10.1371/journal.pone.0082609

Wiatrzyk, A., Polak, M., Czajka, U., KrysztopaGrzybowska, K., and Lutyñska, A. (2013). Phenotypic and genotypic characterization of probiotic bacterial strains used in medicinal products. Med. Dosw. Mikrobiol. 65 47-56.

Wickline, S. (2013). Most Treated for C Diff Don't have Infection. Available online at: www.medpagetoday. com/MeetingCoverage/ASHP/43438
Received: 10 January 2014; accepted: 23 January 2014; published online: 17 February 2014

Citation: Claassen E (2014) Cost-benefit relation of diet and probiotics in iatrogenic bowel irregularity (IBI). Front. Pharmacol. 5:14. doi: 10.3389/fphar.2014.00014 This article was submitted to Pharmaceutical Medicine and Outcomes Research, a section of the journal Frontiers in Pharmacology.

Copyright (c) 2014 Claassen. This is an open-access article distributed under the terms of the Creative Commons Attribution License (CC BY). The use, distribution or reproduction in other forums is permitted, provided the original author(s) or licensor are credited and that the original publication in this journal is cited, in accordance with accepted academic practice. No use, distribution or reproduction is permitted which does not comply with these terms. 